\title{
DPEN \\ Geomorphic contexts and science focus of the Zhurong landing site on Mars
}

\author{
Jianjun Liu ${ }^{1,2}$, Chunlai Li ${ }^{1,2 凶}{ }^{\text {, Rongqiao Zhang }}{ }^{\circledR}$, Wei Rao ${ }^{4}$, Xiaofeng Cui ${ }^{5}$, Yan Geng ${ }^{3}$, Yang Jia ${ }^{4}$, \\ Hai Huang1,2, Xin Ren1, Wei Yan', Xingguo Zeng ${ }^{10}{ }^{1}$, Weibin Wen', Xing Wang,', Xingye Gao', \\ Qiang Fu', Yan Zhu' ${ }^{6}$, Jihong Dong ${ }^{7}$, Haitao Li $^{8}$, Xianzhong Wang ${ }^{9}$, Wei Zuo ${ }^{1,2}$, Yan Su ${ }^{1,2}$, \\ Deqing Kong ${ }^{1}$ and Hongbo Zhang ${ }^{1}$
}

\begin{abstract}
As part of the Tianwen-1 mission, the Zhurong rover successfully touched down in southern Utopia Planitia on 15 May 2021. On the basis of the new sub-metre-resolution images from the High Resolution Imaging Camera on board the Tianwen-1 orbiter, we determined that the Zhurong rover landed at $109.925^{\circ} \mathrm{E}, 25.066^{\circ} \mathrm{N}$ at an elevation of $-4,099.4 \mathrm{~m}$. The landing site is near the highland-lowland boundary ${ }^{1}$ and multiple suspected shorelines ${ }^{2-7}$. Under the guidance of the remote sensing survey, the Zhurong rover is travelling south for specific in situ investigation. Supported by the six payloads on board the rover ${ }^{8}$, its initial key targets are rocks, rocky fields, transverse aeolian ridges and subsurface structures along the path. Extended investigation will aim at troughs and cones in the distance. A better understanding of the formation mechanisms of these targets may shed light on the historical volcanism and water/ice activities within the landing area, as well as the activities of the wind. These results may reveal the characteristics and evolution of the ancient Martian environment and advance the exploration of the habitability of ancient Mars.

Tianwen-1, China's Mars exploration mission, aims to complete orbiting, landing and roving in a single mission. The selection of the landing site is required to satisfy both engineering safety and scientific interest. Therefore, before Tianwen-1 was launched, two wide-range preselected landing areas with significant research value were preliminarily chosen with consideration of the engineering constraints $^{9,10}$ (Supplementary Fig. 1). Within these two preselected areas, detailed evaluation of local elevation, slope, rock distribution, thermal environment and the ability to communicate with Earth was further performed. Two $150 \times 60 \mathrm{~km}^{2}$ areas in the southern Utopia Planitia and the western Elysium Mons were then determined as the primary and alternative candidate landing areas (red and green rectangles in Supplementary Fig. 2a). The primary candidate landing area is near the highland-lowland boundary (HLB) and multiple suspected shorelines (see details in Supplementary Information). Evidence of the potential ancient ocean and the historical geologic activities may be revealed by the in situ investigation of the Zhurong rover.

Before the Zhurong rover landed on Mars, the Tianwen-1 orbiter spent about three months conducting a detailed remote sensing survey on the primary candidate landing area via the High Resolution
\end{abstract}

Imaging Camera (HiRIC). The spatial resolution of the images taken from the altitude of $350 \mathrm{~km}$ is about $70 \mathrm{~cm}$. The digital orthophoto map (DOM) and digital elevation model (DEM) of the entire area were obtained from the forward and backward stereo images from different orbits (Methods). On the basis of these data, the candidate landing area was further reduced to a safety ellipse of $56 \times 22 \mathrm{~km}^{2}$ with an inclination of $1.35^{\circ}$ (Fig. 1a). At 7:18 (Coordinated Universal Time +8 ) on 15 May 2021, the Zhurong rover successfully landed in this area and captured panorama images around the landing site using the onboard Navigation and Terrain Cameras (NaTeCams) (Fig. 1b). Using images acquired by HiRIC on 2 June, the landing site was eventually positioned at $109.925^{\circ} \mathrm{E}, 25.066^{\circ} \mathrm{N}$ at an elevation of $-4,099.4 \mathrm{~m}$ (Fig. 1c, Methods).

To assist in the exploration of the Zhurong rover, the geomorphic and geological contexts within the $150 \times 60 \mathrm{~km}^{2}$ landing area were analysed from the HiRIC-derived DOM and DEM. At least five geomorphic features within the landing area are identified (Fig. 2, Fig. $3 g$ and Supplementary Fig. 3a).

1. Rampart craters. Two distinct rampart craters appear at the north and south ends of the landing area (Fig. 1a). Figure 2a shows the northern rampart impact crater with a diameter of $\sim 9 \mathrm{~km}$ and a depth of $\sim 1.2 \mathrm{~km}$. The overall ejecta flow morphologies of rampart craters have always been considered as evidence for high abundance of volatiles (ice/water) in the target materials $^{11,12}$.

2. Cones. Cones are one of the most significant and controversial landforms in Utopia Planitia. Both isolated cones and clusters are found in the landing area (Fig. $2 \mathrm{~b}$ and Supplementary Fig. 4). The cones in this specific region have been mostly interpreted as cinder cones ${ }^{13}$, mud volcanoes ${ }^{14}$ or pingos ${ }^{15}$. However, the interpretation of the well defined cones in the landing area is inconclusive.

3. Ridges. The ridges distributed in the landing area range from approximately 0.59 to $12.6 \mathrm{~km}$ in length. Figure $2 \mathrm{c}$ shows one of the ridges $\sim 42.7 \mathrm{~km}$ southeast of the landing site. In Utopia Planitia, the ridge-like features are probably attributable to tectonism ${ }^{16}$ and volcanism ${ }^{13}$.

4. Troughs. Several troughs appear in the landing area, ranging from 1.2 to $10 \mathrm{~km}$ in length and from 1 to $20 \mathrm{~m}$ in depth. Two of

${ }^{1}$ Key Laboratory of Lunar and Deep Space Exploration, National Astronomical Observatories, Chinese Academy of Sciences, Beijing, China. ${ }^{2}$ University of Chinese Academy of Sciences, Beijing, China. ${ }^{3}$ Lunar Exploration and Space Engineering Center, Beijing, China. ${ }^{4}$ Beijing Institute of Spacecraft System Engineering, Beijing, China. ${ }^{5}$ Beijing Aerospace Control Center, Beijing, China. ${ }^{6}$ National Space Science Center, Chinese Academy of Sciences, Beijing, China. ${ }^{7}$ Changchun Institute of Optics, Fine Mechanics and Physics, Chinese Academy of Sciences, Jilin, China. ${ }^{8}$ Beijing Institute of Tracking and Telecommunications

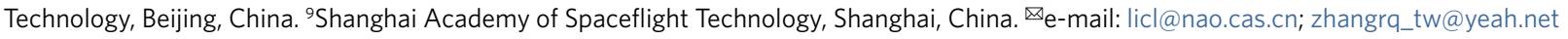




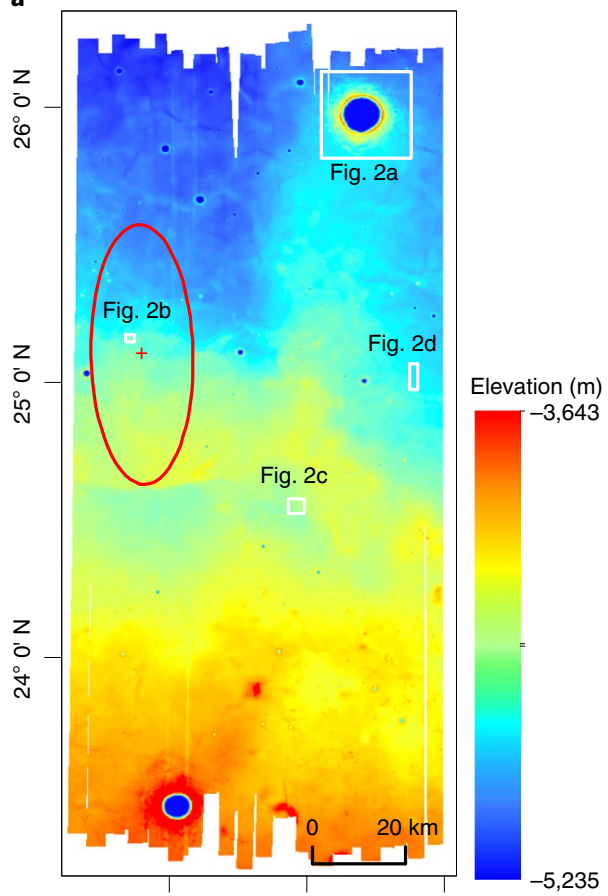

$110^{\circ} 0^{\prime} \mathrm{E} \quad 110^{\circ} 30^{\prime} \mathrm{E} \quad 111^{\circ} 0^{\prime} \mathrm{E}$

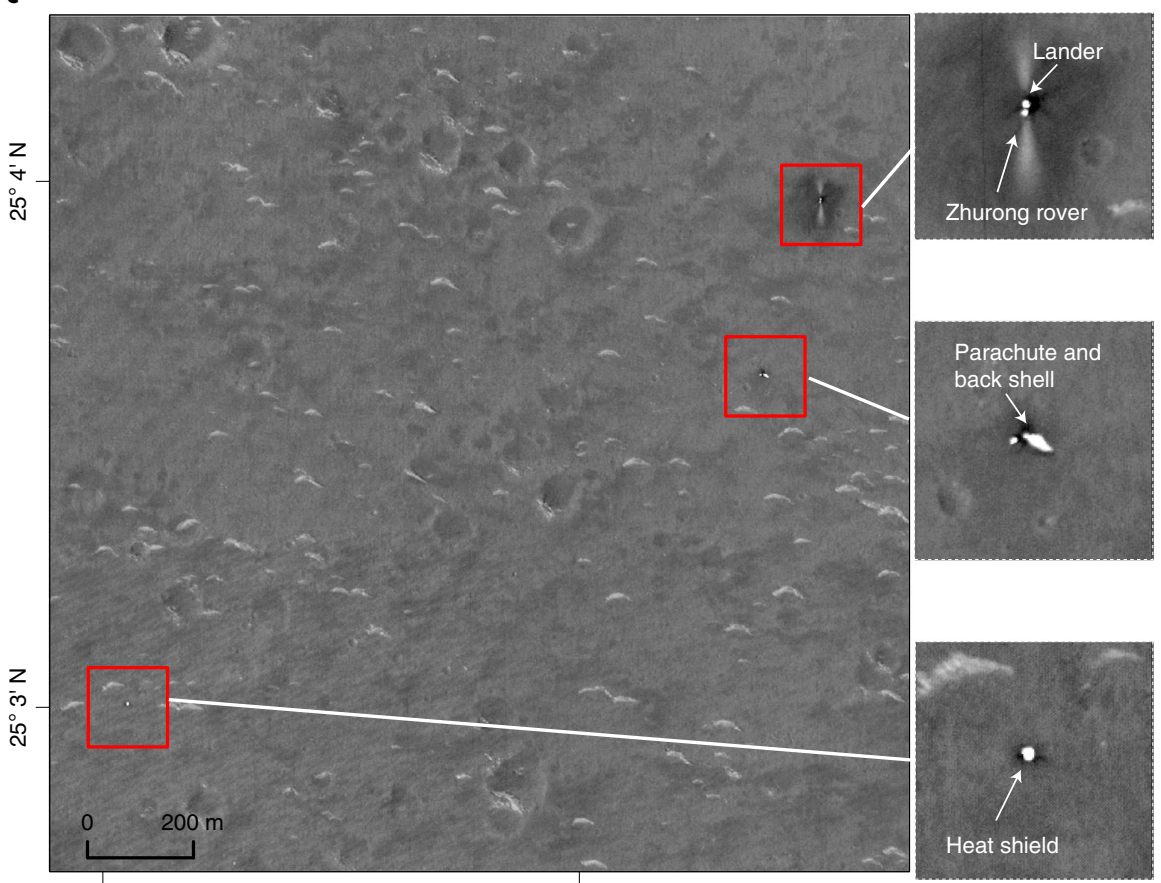

$109^{\circ} 54^{\prime} \mathrm{E}$ $109^{\circ} 55^{\prime} \mathrm{E}$

b

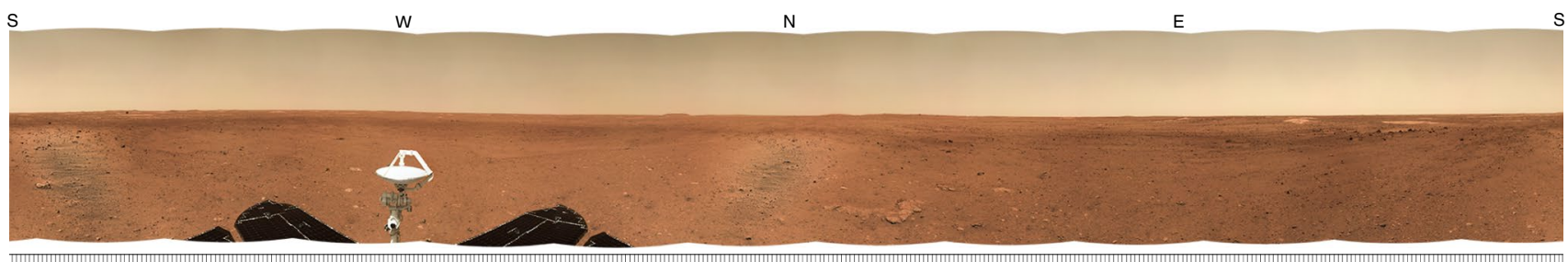

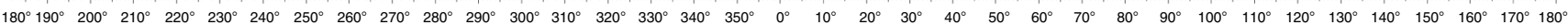

Fig. 1 The primary candidate landing area, location of landing site and panorama around the landing site. a, DEM (3.5 m per pixel) of the landing area derived from HiRIC stereo images. The landing ellipse is marked in red, and is $56 \times 22 \mathrm{~km}^{2}$ with an inclination of $1.35^{\circ}$. The red cross indicates the landing site. White boxes are the locations of the landforms in Fig. 2. b. The first panorama image around the landing site taken by the NaTeCams on board the Zhurong rover. c, View of the Zhurong rover, lander, heat shield and parachute on the HiRIC image acquired on 2 June 2021 . Credit: CNSA/GRAS.

them are shown in Fig. $2 d$ and Supplementary Fig. 3e. Troughs may be associated with polygonal terrains elsewhere in Utopia Planitia ${ }^{17,18}$, but this association is not clear for the cases in the landing area. Moreover, troughs are often modified by aeolian deposits $^{19}$.

5. Transverse aeolian ridges (TARs). High-albedo TARs are common within the landing area, especially in some troughs and craters (Fig. 3c and Supplementary Fig. 3a). Most TARs in the landing area run roughly in the east-west direction, indicating that the local wind was dominant in the north-south direction in the past. Their distribution, morphological characteristics, sediment composition and formation processes are indicators of the local ancient wind field and palaeoenvironment ${ }^{20-22}$.

These landforms identified by the HiRIC images reflect the abundance and complexity of the geological activities in the landing area, probably involving historical volcanism and tectonism, water/ ice activities, wind action and so on. Table 1 summarizes the possible geological factors and materials that could explain the formation of the landforms in the landing area. Such large-scale remote sensing surveys outline the fundamental geological settings of the landing area, strongly supporting the subsequent scientific exploration of the Zhurong rover. Since some landforms have multiple plausible origins and cannot be distinguished by remote sensing detections, in situ investigations using the Zhurong rover are indispensable to obtain additional diagnostic information.

To conduct detailed investigations of thelanding area, the Zhurong rover is equipped with six payloads ${ }^{8}$, including the Mars Rover Penetrating Radar (RoPeR), Mars Rover Magnetometers (RoMAG), Mars Surface Composition Detector (MarSCoDe), Multispectral Camera (MSCam), NaTeCams and Mars Climate Station (MCS). The RoPeR consists of two channels. The low-frequency channel will provide a penetration depth of $10-100 \mathrm{~m}$ with a resolution of a few metres within the Martian soil. The higher-frequency channel is $\mathrm{HH}, \mathrm{HV}, \mathrm{VH}, \mathrm{VV}$ polarization and will penetrate to a depth of 3-10 $\mathrm{m}$ with a resolution of a few centimetres within the Martian soil. The RoPeR will investigate the subsurface structures and even clues to underground water/ice distribution along the roving path ${ }^{23}$. The RoMAG will implement mobile magnetic field measurements on the surface of Mars ${ }^{24}$. Two identical triaxial fluxgate magnetometer sensors are respectively mounted at the top and bottom of the rover mast $(67.5 \mathrm{~cm}$ apart). Each magnetometer measures the vector magnetic field with a resolution of $0.01 \mathrm{nT}$ in the range of $\pm 65,000$ nT. Mobile magnetic field measurements on the Martian surface would obtain the fine-scale crust field and provide information about its remanent magnetization and any possible intrinsic 

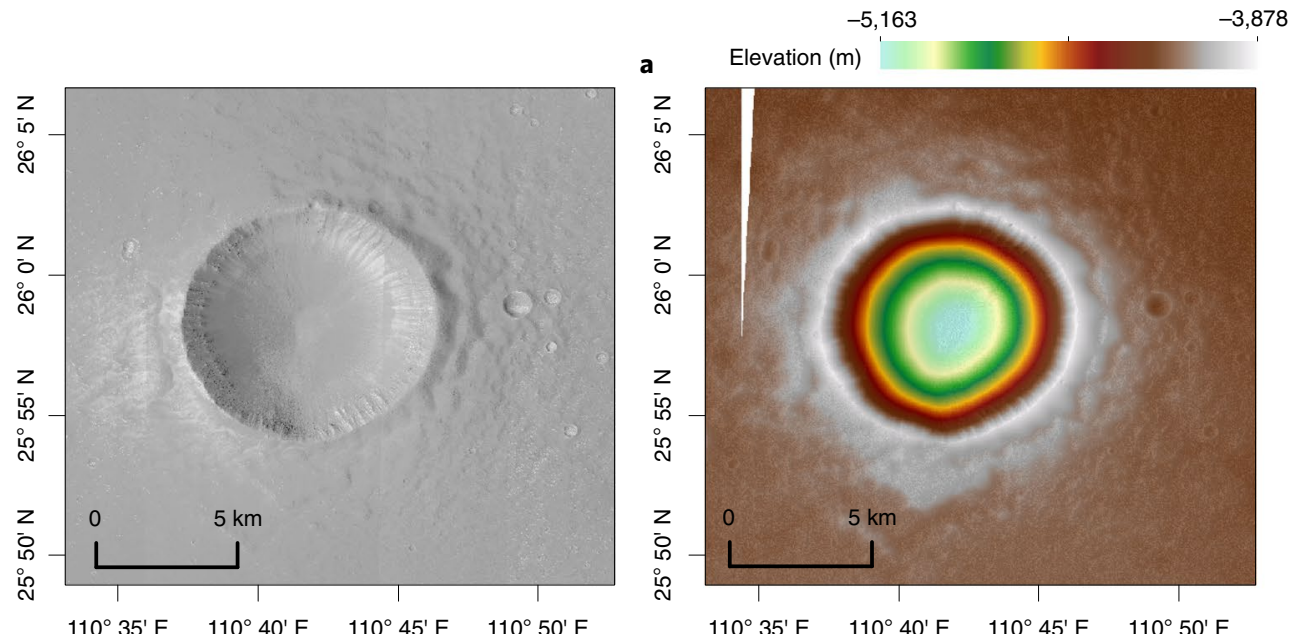

$$
\begin{aligned}
& 110^{\circ} 35^{\prime} \mathrm{E} \quad 110^{\circ} 40^{\prime} \mathrm{E} \quad 110^{\circ} 45^{\prime} \mathrm{E} \quad 110^{\circ} 50^{\prime} \mathrm{E} \\
& -4,144 \quad-4,061
\end{aligned}
$$
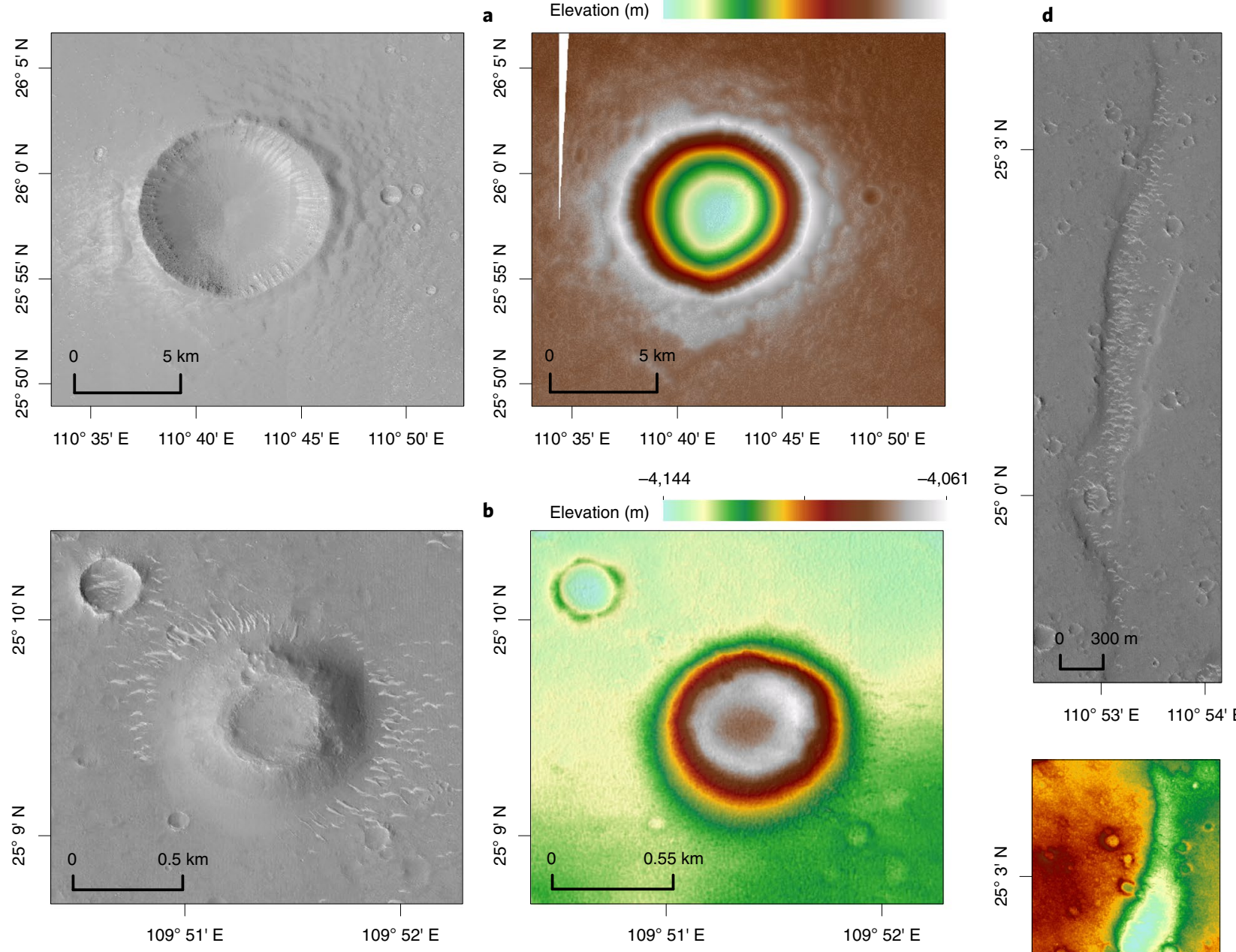

$110^{\circ} 53^{\prime} \mathrm{E} \quad 110^{\circ} 54^{\prime} \mathrm{E}$
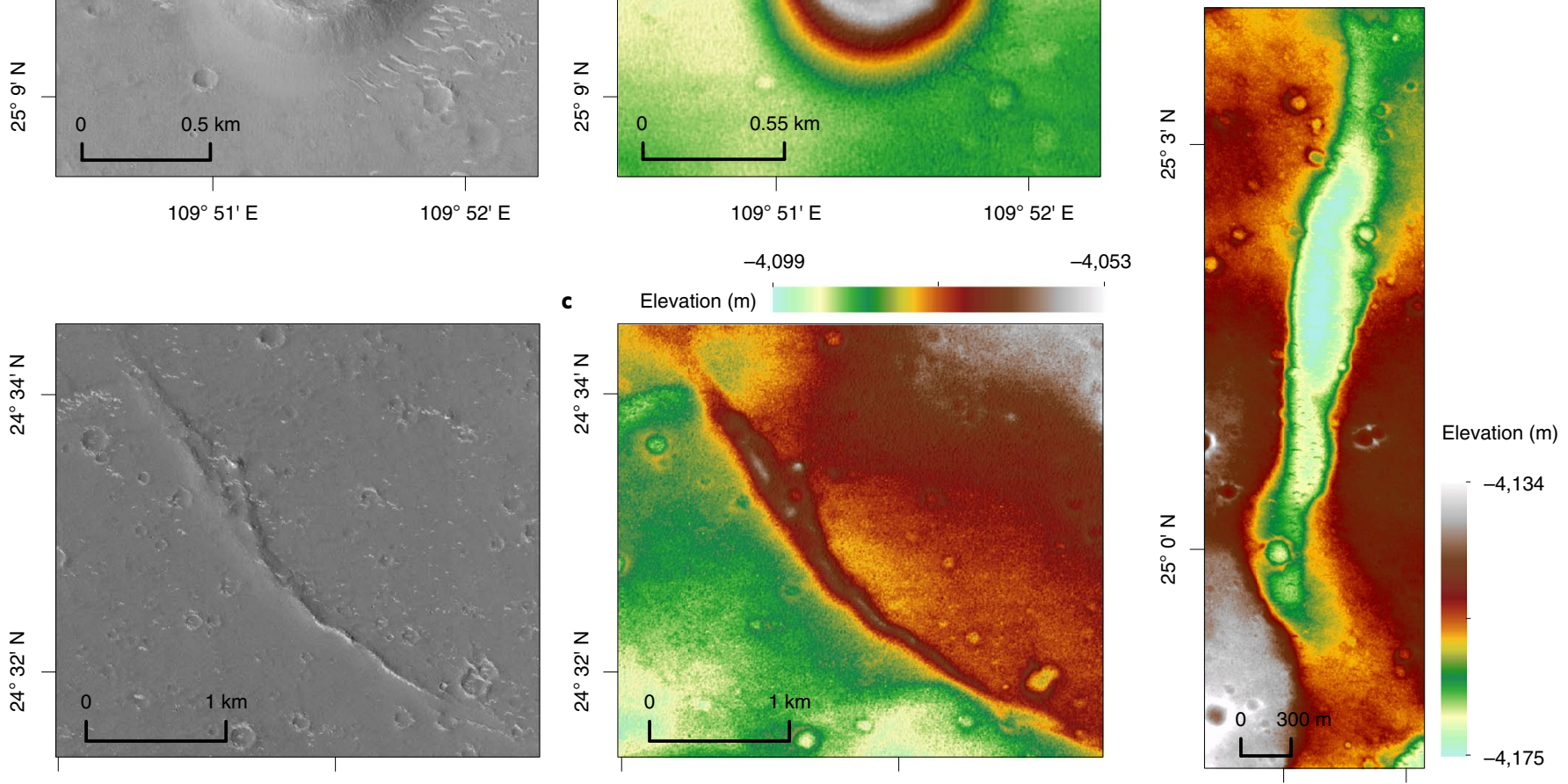

$110^{\circ} 26^{\prime} \mathrm{E}$

$110^{\circ} 28^{\prime} \mathrm{E}$

$110^{\circ} 26^{\prime} \mathrm{E}$

$110^{\circ} 28^{\prime} \mathrm{E}$

$110^{\circ} 53^{\prime} \mathrm{E} \quad 110^{\circ} 54^{\prime} \mathrm{E}$

Fig. 2 | HiRIC-derived DOM and DEM of the geomorphic features in the $150 \times 60 \mathbf{~ k m}^{2}$ landing area. a, A rampart crater with a diameter of $\sim 9 \mathrm{~km}$ and a depth of $\sim 1.2 \mathrm{~km}$, which is located $\sim 66 \mathrm{~km}$ northeast of the landing site. $\mathbf{b}$, An isolated cone with a height of $50 \mathrm{~m}$ appears $\sim 6.4 \mathrm{~km}$ northwest of the landing site. The diameters of its central pit and base are $\sim 450 \mathrm{~m}$ and $\sim 1,100 \mathrm{~m}$, respectively. The flank slope is about $8^{\circ}$. c, A ridge located $\sim 42.7 \mathrm{~km}$ southeast of the landing site. It is $\sim 3.3 \mathrm{~km}$ long and about $4-10 \mathrm{~m}$ in height. $\mathbf{d}$, A trough in the landing area $~ 57 \mathrm{~km}$ northeast of the landing site, which is about $5.2 \mathrm{~km}$ long, approximately 200-661 m wide and 2-20 m deep. Credit: CNSA/GRAS.

magnetic field. The MarSCoDe uses laser-induced breakdown spectroscopy to vaporize rock specimens on the surface with a stand-off distance of $1.6-7 \mathrm{~m}$, revealing their compositions ${ }^{25,26}$ Moreover, the near-infrared spectroscopy at $850-2,400 \mathrm{~nm}$ can conduct reflectance spectrum analysis of Martian soils and rocks, and a telescopic microimager can capture high-resolution images of research targets at different distances. The MSCam, with eight narrow bands and a band for solar imaging, will provide detailed 


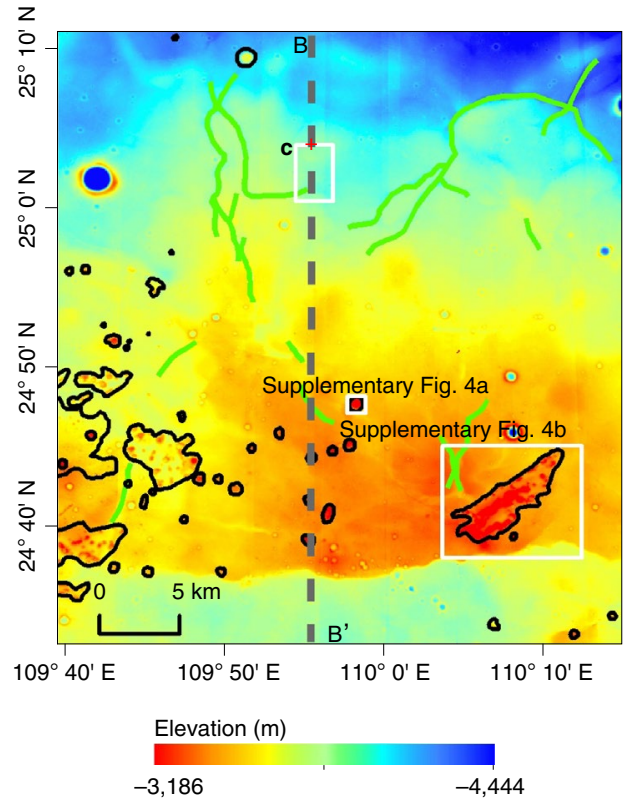

e

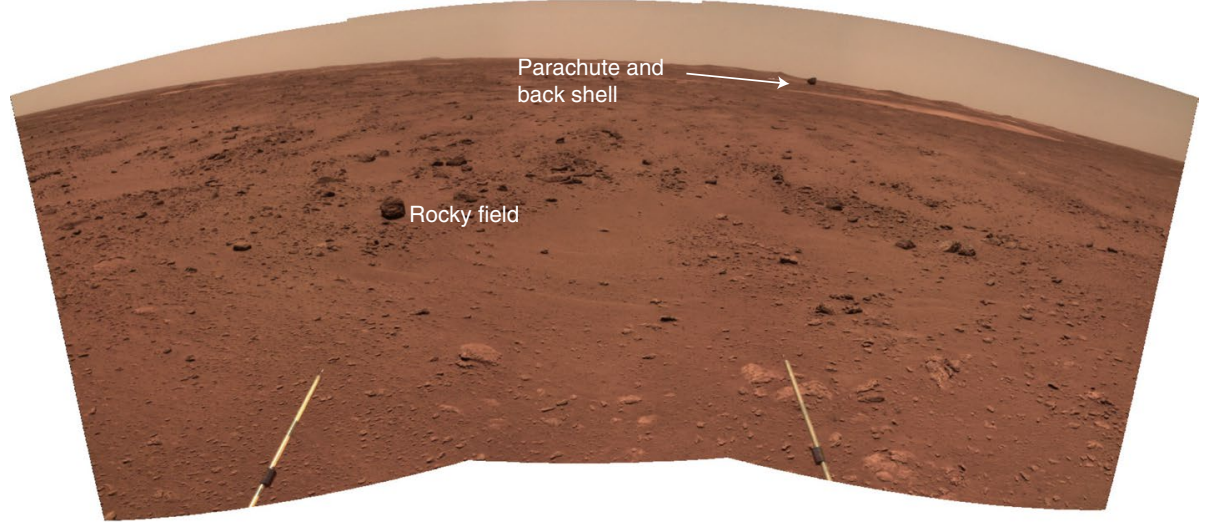

g

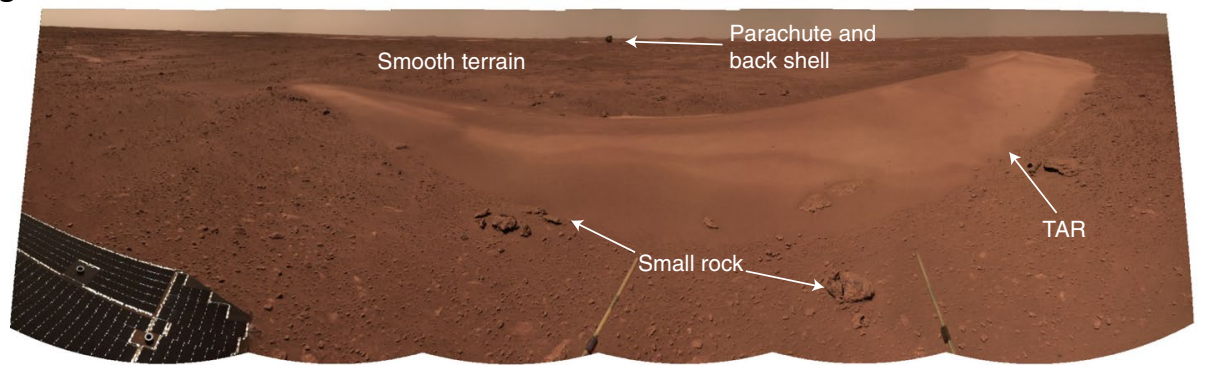

C

d

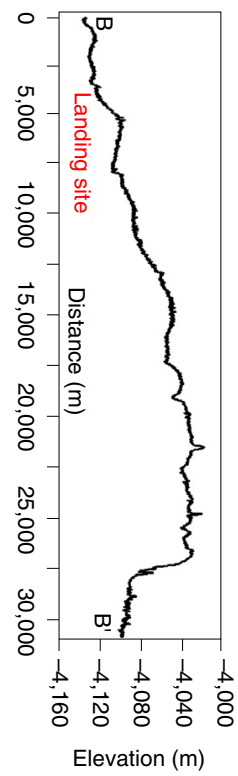

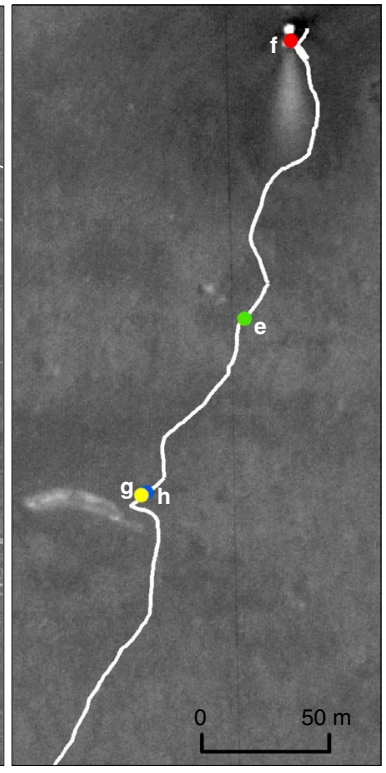

f

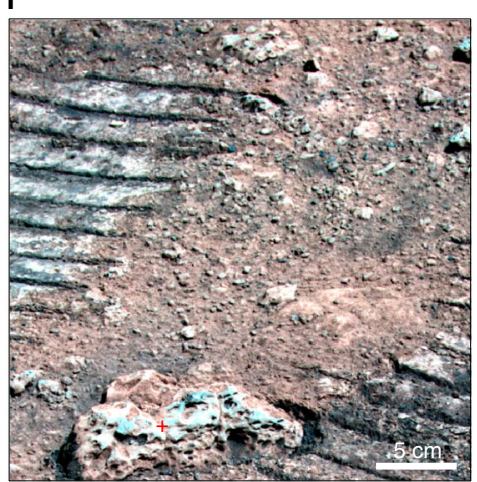

h

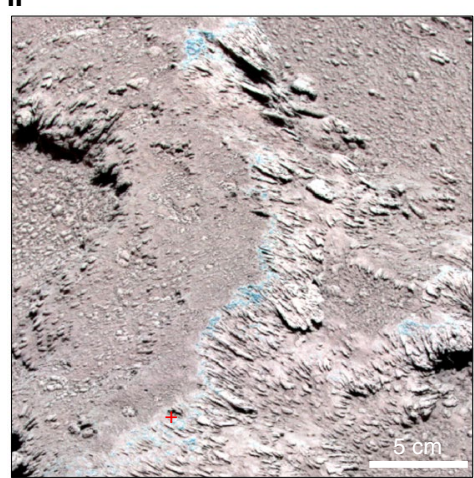

Fig. 3 | Contexts and investigation targets around the Zhurong landing site. a, The topography and major geological features around the landing site $\left(35 \times 38 \mathrm{~km}^{2}\right)$. The red cross indicates the Zhurong landing site. Green solid lines represent the troughs. Cones are outlined with black lines. White boxes mark the positions of $\mathbf{c}$ and Supplementary Fig. 4. b, North-south topographic profile across the Zhurong landing site (dashed grey line B-B' in $\mathbf{a}$ ). $\mathbf{c}$, An accessible investigation region $\left(2.3 \times 3.5 \mathrm{~km}^{2}\right)$. The position of $\mathbf{d}$ is marked with a white dashed box. The white curve represents the route that the rover has travelled. Yellow arrows denote subsequent travelling directions and five detection targets. d, A detailed view of the current travelling route of the rover; the coloured points represent the locations where images $\mathbf{e}-\mathbf{h}$ were taken. $\mathbf{e}, \mathbf{g}$, Panoramas taken by the NaTeCams showing the rocky field and a barchan-like TAR. f,h, The rock images collected by the MSCam (R $650 \mathrm{~nm}, \mathrm{G} 525 \mathrm{~nm}$, B 480 nm); the exposed rock surfaces may be modified by wind erosion. Note that the red crosses on the images represent the detection positions of MarSCoDe; the targets are the rock surfaces with less dust coverage. Credit: CNSA/GRAS.

information on the geological context, material composition and surface texture ${ }^{8}$. The NaTeCams are binocular stereo cameras with $270 \mathrm{~mm}$ stereo baseline, $13.1 \mathrm{~mm}$ focal length, 2,048 $\times 2,048$ pixels and $46.5^{\circ} \times 46.5^{\circ}$ field of view ${ }^{27}$. The MCS will measure the temperature, pressure, wind speed, wind direction and sound on the Martian surface ${ }^{28}$. 


\begin{tabular}{|c|c|c|c|c|c|c|c|}
\hline \multirow[t]{2}{*}{ Landforms } & \multicolumn{5}{|l|}{ Factors } & \multicolumn{2}{|l|}{ Materials } \\
\hline & $\begin{array}{l}\text { Impact } \\
\text { related }\end{array}$ & $\begin{array}{l}\text { Volcanism } \\
\text { related }\end{array}$ & $\begin{array}{l}\text { Fluviation } \\
\text { related }\end{array}$ & $\begin{array}{l}\text { Aeolian } \\
\text { related }\end{array}$ & $\begin{array}{l}\text { Tectonism } \\
\text { related }\end{array}$ & $\begin{array}{l}\text { Water/ice } \\
\text { related }\end{array}$ & $\begin{array}{l}\text { Heat source } \\
\text { related }\end{array}$ \\
\hline Rampart crater & $\mathrm{H}$ & L & $\mathrm{L}$ & L & L & $\mathrm{H}$ & L \\
\hline Cones & L & $\mathrm{H}$ & $L$ & L & L & $\mathrm{H}$ & $\mathrm{H}$ \\
\hline Ridges & $\mathrm{L}$ & $\mathrm{H}$ & $\mathrm{L}$ & L & $\mathrm{H}$ & $\mathrm{L}$ & $\mathrm{H}$ \\
\hline Troughs & $\mathrm{L}$ & $\mathrm{H}$ & $\mathrm{H}$ & $\mathrm{H}$ & $\mathrm{H}$ & $\mathrm{H}$ & $\mathrm{H}$ \\
\hline TARs & $\mathrm{L}$ & $\mathrm{L}$ & $\mathrm{L}$ & $\mathrm{H}$ & L & $\mathrm{L}$ & $\mathrm{L}$ \\
\hline
\end{tabular}

After the successful landing in southern Utopia Planitia, the six payloads on board the Zhurong rover have been switched on and tested. Under the guidance of the remote sensing survey, the Zhurong rover is travelling south for specific in situ investigations, gradually approaching the direction of the HLB and the suspected shorelines. The Zhurong rover may find out if there are any traces of ancient oceans. For example, (1) the low dielectric constant compared with that of the typical volcanic materials may indicate low-density sedimentary deposits, massive deposits of ground ice or a combination of the $\mathrm{two}^{29} ;$ (2) hydrated minerals, water-related sedimentary rocks and textures, and alteration minerals may reveal early water activities ${ }^{5}$; (3) some of the anomalous chemistry (such as unusual abundances of $\mathrm{S}$ and $\mathrm{Cl}$ and their possible presence as sulfate minerals and chloride salts) may be related to the presence of former standing bodies of water ${ }^{30}$. Currently, the rover travels about $20-30 \mathrm{~m}$ per sol and had travelled about $700 \mathrm{~m}$ by the end of July 2021. Given the capacity and good condition of the rover, an accessible region was selected as the investigation region for the nominal and short-term extended mission phases, which is shown in Fig. 3c.

The major detection targets of the Zhurong rover are the rocks along the path (Fig. 3f,h). The onboard NaTeCams will preliminarily investigate the terrains around the rover and determine the locations and shapes of the target rocks. The rocks excavated by small impacts or covered in less dust will be the preferred targets. Then the powerful tools MSCam and MarSCoDe will be employed to identify the compositions and physical properties of the rocks. The fine-scale structures, particle sizes and alteration minerals will restrict the geological background of the landing area and may provide indirect evidence of the ancient ocean. Furthermore, the degree and characteristics of wind erosion on the rock surface are helpful to study the paleoenvironment around the landing area.

In the nominal mission phase, some intriguing features in the investigation region will also be targets, such as TARs and rocky fields (regions 1, 2 and 3 in Fig. 3c). The rover has encountered a barchan-like TAR $\sim 200 \mathrm{~m}$ southwest of the landing site, with a height of $\sim 0.6 \mathrm{~m}, \sim 50 \mathrm{~m}$ in length and $\sim 8 \mathrm{~m}$ in width (Fig. $3 \mathrm{~g}$ and Supplementary Fig. 3a). The NaTeCams on board the rover will obtain its three-dimensional geomorphology, while MSCam and MarSCoDe will reveal the composition and particle size sorting of the sand. The MSC will further help monitor the current wind field nearby. This information is of great significance to establish the basic development model of Martian sand dunes. Two wide rocky fields showing rough textures with different albedo are present in the high-resolution images, located $\sim 624 \mathrm{~m}$ and $\sim 1,014 \mathrm{~m}$ from the landing site, respectively (Fig. $3 e$ and Supplementary Fig. $3 \mathrm{~b}, \mathrm{c})$. Unlike nearby smooth terrains, there are many rock fragments exposed here. The difference in the subsurface structures and underground rock distribution between the rocky fields and smooth terrains will be revealed by the RoPeR.
Subsequently, the Zhurong rover will enter the extended mission phase. The short-term targets in this phase are another narrow rocky field and a trough with the maximum depth of $\sim 10 \mathrm{~m}$, which are located $\sim 1.8 \mathrm{~km}$ and $\sim 2.7 \mathrm{~km}$ south of the landing site, respectively (regions 4 and 5 in Fig. $3 \mathrm{c}$ and Supplementary Fig. 3d,e). In the longer term, we expect that the rover will travel further. From the DEM data, the elevation is constantly rising as the rover travels south. The height difference between the landing site and the highest point is $\sim 60 \mathrm{~m}$, and a scarp appears $\sim 27 \mathrm{~km}$ away from the landing site. Many cone features are distributed near the scarp, especially clustered cones (Fig. 3a,b and Supplementary Fig. 4), indicating that this region may have been geologically active in the past. However, how the terrain formed remains unknown. Further research combining remote sensing data from the Tianwen-1 orbiter and in situ data from the Zhurong rover will address these questions. These results may reveal the characteristics and evolution of the ancient Martian environment and advance the exploration of the habitability of ancient Mars.

\section{Methods}

Landing area topography reconstruction and landing site positioning. Tianwen-1 successfully entered the parking orbit of Mars on 24 February 2021. Before the Zhurong rover landed on the Martian surface, the HiRIC on the orbiter imaged the primary candidate landing area 21 times (including 11 forward-view images and 10 backward-view images to construct stereoscopic images). Each image has a width of about $11 \mathrm{~km}$ and a length of $170 \mathrm{~km}$ in the north-south direction. These images realized multiview stereo coverage of the $150 \times 60 \mathrm{~km}^{2}$ primary candidate landing area. On 2 June, to determine the accurate position of the Zhurong rover, HiRIC carried out a $10 \mathrm{~s}$ imaging with a width of about $11 \mathrm{~km}$ and a north-south length of about $43 \mathrm{~km}$. The spatial resolution of the above images is about $0.6-1.2 \mathrm{~m}$.

We produced a DOM with a spatial resolution of $0.7 \mathrm{~m}$ and a DEM with a spatial resolution of $3.5 \mathrm{~m}$ of the primary candidate landing area using these multiview stereo images by photogrammetric processing. The data processing flow is as follows.

1. The imaging geometric model of HiRIC (rational polynomial coefficients model) was constructed on the basis of its geometric calibration parameters and the orientation parameters of the Tianwen-1 orbiter, such as its position and attitude. Then the rigorous geometric relationship between the image points and their corresponding feature points on the Martian surface can be established.

2. Feature point matching of HiRIC images. Scale-invariant feature transform ${ }^{3}$ feature matching is used here to extract connection points between the forward-view and backward-view images in the same imaging area, and in the overlapping areas between adjacent imaging areas. The mismatches were eliminated by a more precise matching process, such as least squares matching.

3. The Mars Reconnaissance Orbiter (MRO) CTX (Context Camera) image in $^{32}$ with a spatial resolution of $6 \mathrm{~m}$ is used as the horizontal position control datum to extract dozens of control points between the forward-view and backward-view images. The elevation for these control points was adopted from the MRO Mars Orbiter Laser Altimeter (MOLA) terrain data ${ }^{33}$ with a spatial resolution of $200 \mathrm{~m}$, whose elevation accuracy is $\pm 3 \mathrm{~m}$.

4. HiRIC images were divided into blocks, and block adjustment was performed on the basis of the photogrammetric bundle adjustment technology ${ }^{34,35}$. The external orientation elements were optimized to realize the seamless mosaic and high-precision absolute positioning for the HiRIC images. 
5. Optimized exterior orientation elements were used to establish the epipolar geometric constraint between the forward-view and backward-view images so that corresponding image points could be matched pixel by pixel. The three-dimensional coordinates of each corresponding point were calculated by the forward ray intersection. Then a regular grid of DEM data was produced using inverse distance weighting, with a spatial resolution of $3.5 \mathrm{~m}$.

6. According to the strict geometric imaging model of HiRIC, the forward- and backward-view images were orthorectified using DEM data to produce DOM data, with a spatial resolution of $0.7 \mathrm{~m}$.

According to the photogrammetric adjustment results, the s.d. of the horizontal position error of the preselected landing area topographic data produced by the HiRIC images is about $0.4 \mathrm{~m}$, and the s.d. of the elevation error is about $1.0 \mathrm{~m}$. Compared with MRO CTX image data, the horizontal position deviation (root mean squared) is $15 \mathrm{~m}$, while the elevation deviation (root mean squared) is about $10 \mathrm{~m}$ compared with MRO MOLA data.

According to the orthophoto image from the HiRIC obtained on 2 June, the accurate horizontal position of the landing site was determined, and its elevation was measured on the DEM mentioned above. The determined landing site of Tianwen- 1 is $109.925^{\circ} \mathrm{E}, 25.066^{\circ} \mathrm{N}$, with an elevation of $-4,099.4 \mathrm{~m}$. The coordinate system used here takes the Mars centre of mass as the origin; the reference surface of the elevation is the surface of a spheroid with a radius of $3,396.19 \mathrm{~km}$ and the reference plane is the equatorial plane of Mars. Its $X$ axis, $Y$ axis and $Z$ axis are parallel to the corresponding three axes of the Martian fixed coordinate system, which is based on the International Astronomical Union orientation parameter model $^{36}$.

\section{Data availability}

The Tianwen-1 data used in this work is processed and produced by the Ground Research and Application System (GRAS) of China's Lunar and Planetary Exploration Program, provided by China National Space Administration (http:// moon.bao.ac.cn). The data used in this manuscript are available at https://moon. bao.ac.cn/web/enmanager/zygj. Datasets generated or analysed during this study are available from the corresponding author upon reasonable request. Source data are provided with this paper.

Received: 18 June 2021; Accepted: 17 September 2021; Published online: 6 December 2021

\section{References}

1. Tanaka, K. L. et al. Geologic Map of Mars: Pamphlet to Accompany Scientific Investigations Map 3292 (USGS, 2014).

2. Sholes, S. F., Dickeson, Z. I., Montgomery, D. R. \& Catling, D. C. Where are Mars' hypothesized ocean shorelines? Large lateral and topographic offsets between different versions of paleoshoreline maps. J. Geophys. Res. Planets 126, e2020JE006486 (2021).

3. Ivanov, M. A., Hiesinger, H., Bernhardt, H., Reiss, D. \& Reiss, D. Topography of the Deuteronilus contact on Mars: evidence for an ancient water/mud ocean and long-wavelength topographic readjustments. Planet. Space Sci. 144, 49-70 (2017).

4. Perron, J. T., Mitrovica, J. X., Manga, M., Matsuyama, I. \& Richards, M. A. Evidence for an ancient Martian ocean in the topography of deformed shorelines. Nature 447, 840-843 (2007).

5. Carr, M. H. \& Head, J. W. Oceans on Mars: an assessment of the observational evidence and possible fate. J. Geophys. Res. 108, E5 (2003).

6. Clifford, S. \& Parker, T. J. The evolution of the Martian hydrosphere: implications for the fate of a Primordial ocean and the current state of the Northern Plains. Icarus 154, 40-79 (2001).

7. Parker, T. J., Gorsline, D. S., Saunders, R. S., Pieri, D. C. \& Schneeberger, D. M. Coastal geomorphology of the Martian northern plains. J. Geophys. Res. Planets 98, 11061-11078 (1993).

8. Li, C. et al. China's Mars exploration mission and science investigation. Space Sci. Rev. 217, 57 (2021).

9. Ye, P. J., Sun, Z. Z., Rao, W. \& Meng, L. Z. Mission overview and key technologies of the first Mars probe of China. Sci. China Technol. Sci. 60, 649-657 (2017).

10. Dong, J. et al. Mission profile and design challenges of Mars landing exploration. Int. Archives Photogramm. Remote Sens. Spat. Inf. Sci. XLII-3/ W1, 35-39 (2017).

11. Mouginis-Mark, P. J. Morphology of Martian rampart craters. Nature 272, 691-694 (1978).

12. Stewart S. T., O'Keefe J. D. \& Ahrens T. J. The relationship between rampart crater morphologies and the amount of subsurface ice. In 32nd Lunar and Planetary Science Conference abstr. no.2092 (Lunar and Planetary Institute, 2001).

13. Lanz, J. K., Wagner, R., Wolf, U., Kröchert, J. \& Neukum, G. Rift zone volcanism and associated cinder cone field in Utopia Planitia, Mars. J. Geophys. Res. Planets 115, E12 (2010).
14. Ivanov, M. A., Hiesinger, H., Erkeling, G. \& Reiss, D. Mud volcanism and morphology of impact craters in Utopia Planitia on Mars: evidence for the ancient ocean. Icarus 228, 121-140 (2014).

15. Pablo, M. A. \& Komatsu, G. Possible pingo fields in the Utopia basin, Mars: geological and climatical implications. Icarus 199, 49-74 (2009).

16. Thomson, B. J. \& Head, J. W. III Utopia Basin, Mars: characterization of topography and morphology and assessment of the origin and evolution of basin internal structure. J. Geophys. Res. Planets 106, 23209-23230 (2001).

17. Séjourné, A. et al. Scalloped depressions and small-sized polygons in western Utopia Planitia, Mars: a new formation hypothesis. Planet. Space Sci. 59, 412-422 (2011)

18. McGill, G. E. \& Hills, L. S. Origin of giant Martian polygons. J. Geophys. Res. Planets 97, 2633-2647 (1992).

19. Hiesinger, H. \& Head, J. W. III Characteristics and origin of polygonal terrain in southern Utopia Planitia, Mars: results from Mars Orbiter Laser Altimeter and Mars Orbiter Camera data. J. Geophys. Res. Planets 105, 11999-12022 (2000).

20. Bourke, M. C., Wilson, S. A. \& Zimbelman, J. R. The variability of TARs in troughs on Mars. In 34th Lunar and Planetary Science Conference abstr. no.1050 (Lunar and Planetary Institute, 2003).

21. Berman, D. C., Balme, M. R., Rafkin, S. C. \& Zimbelman, J. R. Transverse aeolian ridges (TARs) on Mars II: distributions, orientations, and ages. Icarus 213, 116-130 (2011).

22. Balme, M., Berman, D. C., Bourke, M. C. \& Zimbelman, J. R. Transverse aeolian ridges (TARs) on Mars. Geomorphology 101, 703-720 (2008).

23. Zhou, B. et al. The Mars rover subsurface penetrating radar onboard China's Mars 2020 mission. Earth Planet. Phys. 4, 345-354 (2020).

24. $\mathrm{Du}, \mathrm{A}$. M. et al. The Chinese Mars rover fluxgate magnetometers. Space Sci. Rev. 216, 135 (2020).

25. Wan, X. et al. Design, function, and implementation of China's first LIBS Instrument (MarSCoDe) on the Zhurong Mars Rover. At. Spectrosc. https:// doi.org/10.46770/AS.2021.608 (2021).

26. Xu, W. et al. The MarSCoDe instrument suite on the Mars rover of China's Tianwen-1 mission. Space Sci. Rev. 217, 64 (2021).

27. Liang, X. et al. The Navigation and Terrain Cameras on the Tianwen-1 Mars rover. Space Sci. Rev. 217, 37 (2021).

28. Peng, Y. Q. et al. Overview of the Mars Climate Station for Tianwen-1 mission. Earth Planet. Phys. 4, 371-383 (2020).

29. Mouginot, J., Pommerol, A., Beck, P., Kofman, W. \& Clifford, S. M. Dielectric map of the Martian northern hemisphere and the nature of plain filling materials. Geophys. Res. Lett. 39, L02202 (2012).

30. Head, J. W. et al. Possible ancient oceans on Mars: evidence from Mars Orbiter Laser Altimeter data. Science 286, 2134-2137 (1999).

31. Lowe, D. G. Distinctive image features from scale-invariant keypoints. Int. J. Comput. Vis. 60, 91-110 (2004).

32. Dickson, J. L. et al. The global CTX mosaic of Mars: lessons for the construction and dissemination of massive imaging data sets. In 51st Lunar and Planetary Science Conference abstr. no.2309 (Lunar and Planetary Institute, 2020).

33. Fergason, R. L., Hare, T. M., \& Laura, J. Mars MGS MOLA-MEX HRSC Blended DEM Global 200m v2 Astrogeology PDS Annex (USGS, 2018); http:// bit.ly/HRSC_MOLA_Blend_v0

34. Wang, Z. Z. Principles of Photogrammetry [with Remote Sensing] (Press of Wuhan Technical Univ. Surveying and Mapping-Publishing House of Surveying and Mapping, 1990).

35. Brown, D. C. A Solution to the General Problem of Multiple Station Analytical Stereo-Angulation Air Force Missile Test Center Report No. 58-8 (Patrick AFB, 1958).

36. Seidelmann, P. K. et al. Report of the IAU/IAG Working Group on Cartographic Coordinates and Rotational Elements of the Planets and Satellites: 2000. Celest. Mech. Dyn. Astron. 82, 83-111 (2002).

37. Smith, D. E. et al. Mars Orbiter Laser Altimeter: experiment summary after the first year of global mapping of Mars. J. Geophys. Res. 106, 23689-23722 (2001).

\section{Acknowledgements}

This work was supported by the China National Space Administration (CNSA). We thank the team members of the five systems of the Tianwen-1 mission: the probe system, the launch vehicle system, the launch site system, the Telemetry Track and Command System and the Ground Research and Application System. This research was also funded by the Key Research program of Chinese Academy of Sciences (grant no. ZDBS-SSW-TLC001)

\section{Author contributions}

C.L., R.Z., J.L. and Y.G. designed the research. J.L., C.L., H.H. and X.W. performed data analysis and made major contributions to writing the manuscript. W.R., X.C., Y.J., H.L., X.W., W.W., Q.F., Y.Z. and J.D. helped with spacecraft and instrument operations and acquired HiRIC and NaTeCam data. X.R., W.Y., X.Z., X.G., W.Z., Y.S., D.K. and H.Z. helped with data receiving, data processing and topography reconstruction. 


\section{Competing interests}

The authors declare no competing interests.

\section{Additional information}

Extended data is available for this paper at https://doi.org/10.1038/s41550-021-01519-5. Supplementary information The online version contains supplementary material available at https://doi.org/10.1038/s41550-021-01519-5.

Correspondence and requests for materials should be addressed to Chunlai Li or Rongqiao Zhang.

Peer review information Nature Astronomy thanks Alfred McEwen and the other, anonymous, reviewer(s) for their contribution to the peer review of this work.

Reprints and permissions information is available at www.nature.com/reprints.
Publisher's note Springer Nature remains neutral with regard to jurisdictional claims in published maps and institutional affiliations.

(c) (i) Open Access This article is licensed under a Creative Commons

Attribution 4.0 International License, which permits use, sharing, adaptation, distribution and reproduction in any medium or format, as long as you give appropriate credit to the original author(s) and the source, provide a link to the Creative Commons license, and indicate if changes were made. The images or other third party material in this article are included in the article's Creative Commons license, unless indicated otherwise in a credit line to the material. If material is not included in the article's Creative Commons license and your intended use is not permitted by statutory regulation or exceeds the permitted use, you will need to obtain permission directly from the copyright holder. To view a copy of this license, visit http://creativecommons. org/licenses/by/4.0/.

(c) The Author(s) 2021 


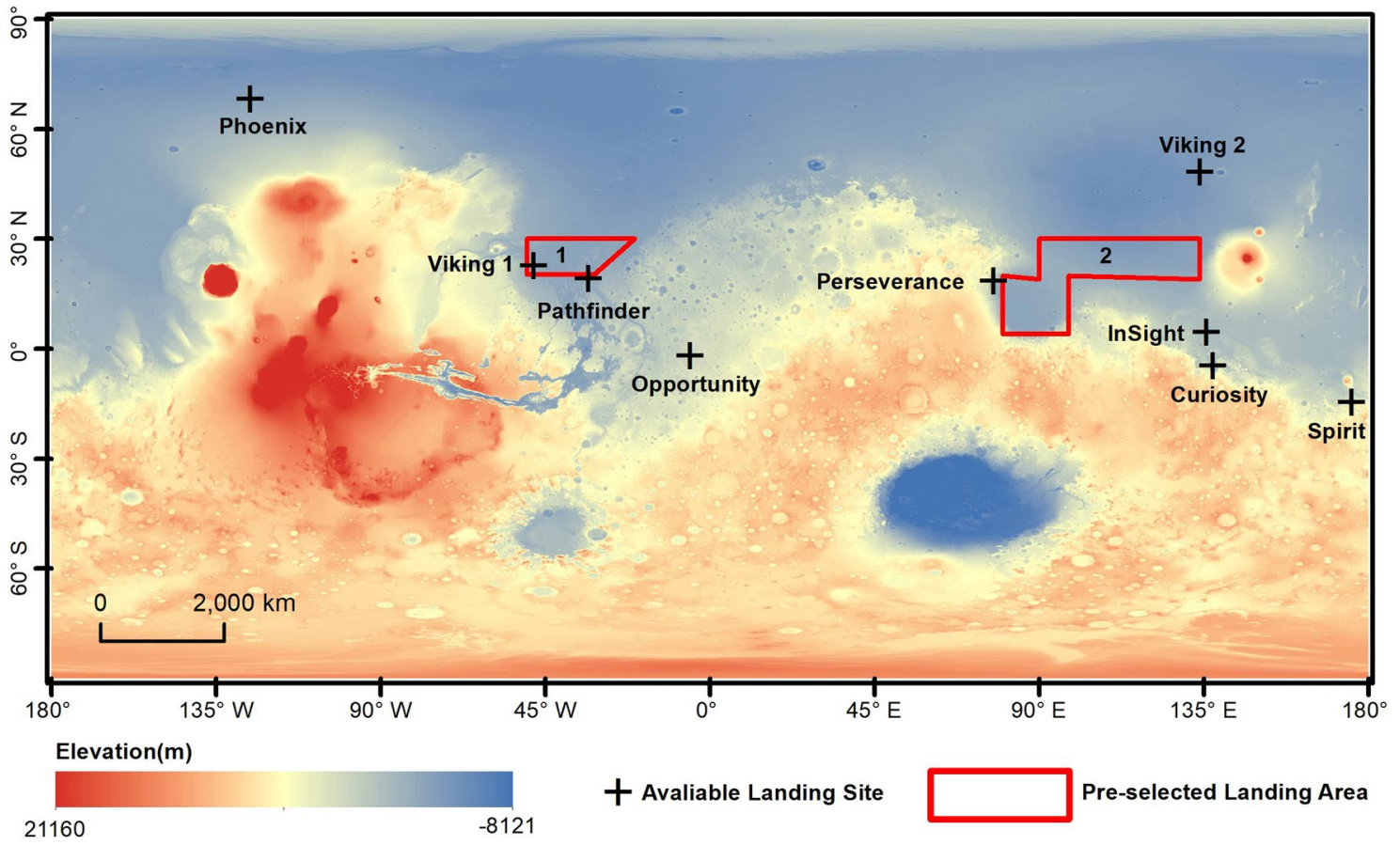

Extended Data Fig. 1 | Two wide-range preselected landing areas of Tianwen-1 mission. The preselected landing area 1 is located in the Chryse Planitia and the preselected landing area 2 is located partly in Isidis planitia and partly in Utopia Planitia (base map is MOLA DEM ${ }^{37}$, which is available at https:// astrogeology.usgs.gov/search/map/Mars/GlobalSurveyor/MOLA/Mars_MGS_MOLA_DEM_mosaic_global_463m). 

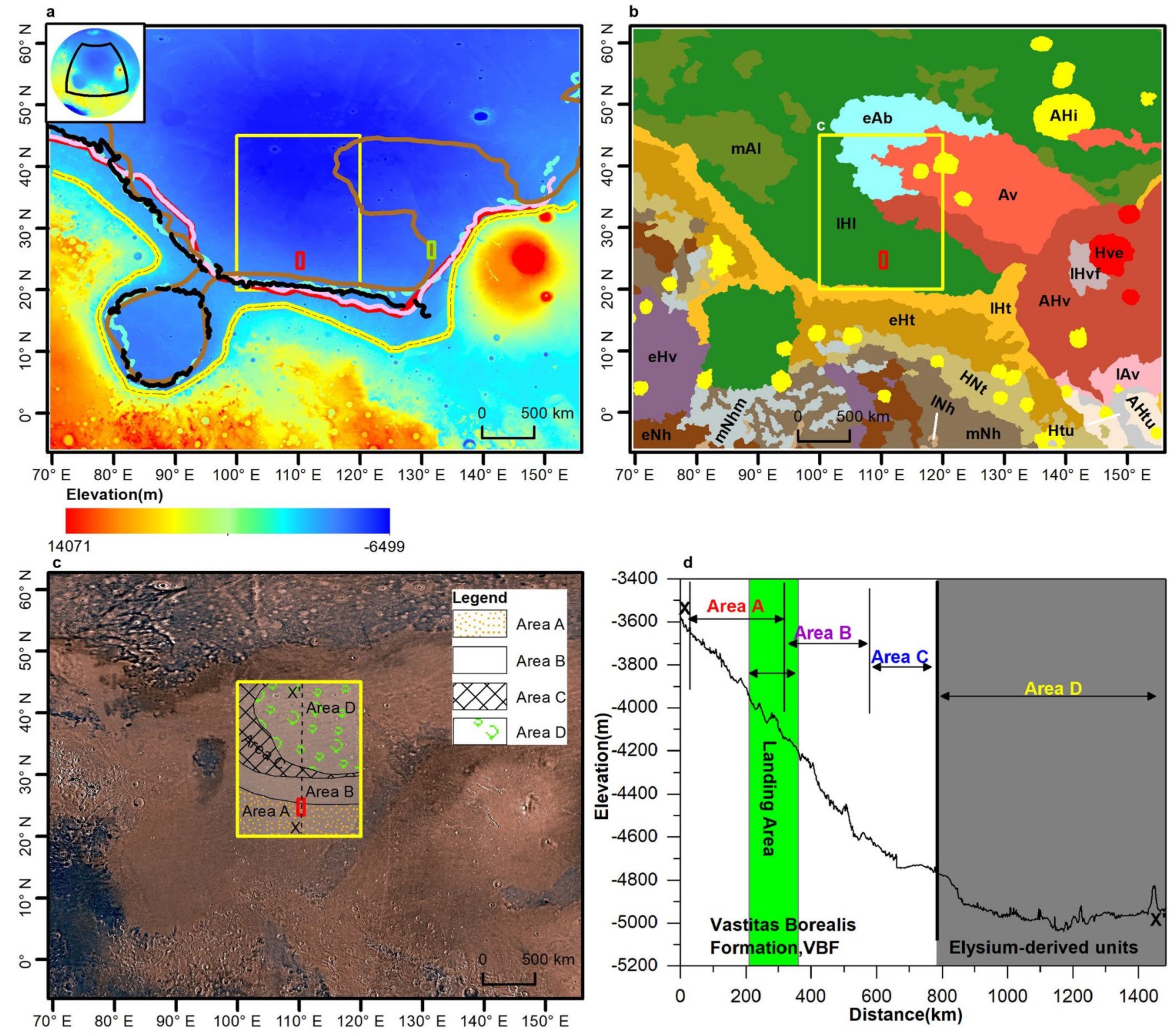

Extended Data Fig. 2 | The geological background of Zhurong landing area. a, Red rectangle centred at $24.7^{\circ} \mathrm{N}, 110.3^{\circ} \mathrm{E}\left(150 \times 60 \mathrm{~km}{ }^{2}\right)$ represents the primary landing area and green rectangle centered at $26.5^{\circ} \mathrm{N}, 131.6^{\circ} \mathrm{E}\left(150 \times 60 \mathrm{~km}^{2}\right)$ represents the alternative landing area. Zhurong rover finally landed in the primary landing area. The landing area is in the southern Utopia Planitia (yellow rectangle, $20^{\circ} \mathrm{N}-45^{\circ} \mathrm{N}, 100^{\circ} \mathrm{E}-120^{\circ} \mathrm{E}$ ), which is near the HLB (yellow line') and the multiple suspected shorelines (lines in black ${ }^{19}$, red ${ }^{20}$, pink $^{21}$, cyan $^{22}$ and brown ${ }^{23}$ ). The base map is MOLA DEM ${ }^{37}$. b, Geological map (adapted from Tanaka et al. 2014) of the landing area and surrounding area. All regions are consistent with Supplementary Fig. 2a. The landing area is within the $\mathrm{IHI}$ unit. c, Zoning map of the landforms around the landing area $^{3}$ (adapted from Ivanov et al. 2014). The coverage area corresponds to the yellow rectangle in Supplementary Fig. 2a and 2b. The base map is Viking Global Mosaic, which is available at https://astrogeology.usgs.gov/search/map/ Mars/Viking/MDIM21/Mars_Viking_MDIM21_ClrMosaic_global_232m.d, North-south topographic profile across the landing area in southern UP ( $X-X^{\prime}$ gray dashed line in Supplementary Fig. 2c). The landing area is located in the transition zone between Area A and Area B, with an elevation range from -3900 to $4150 \mathrm{~m}$. 
a

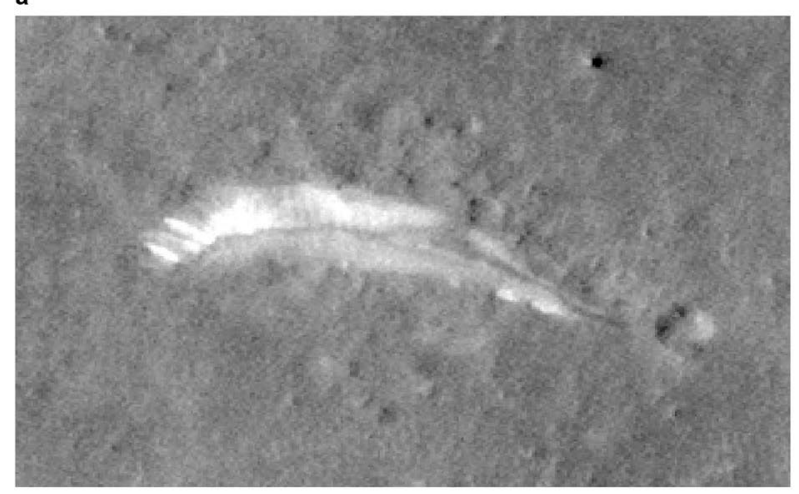

c

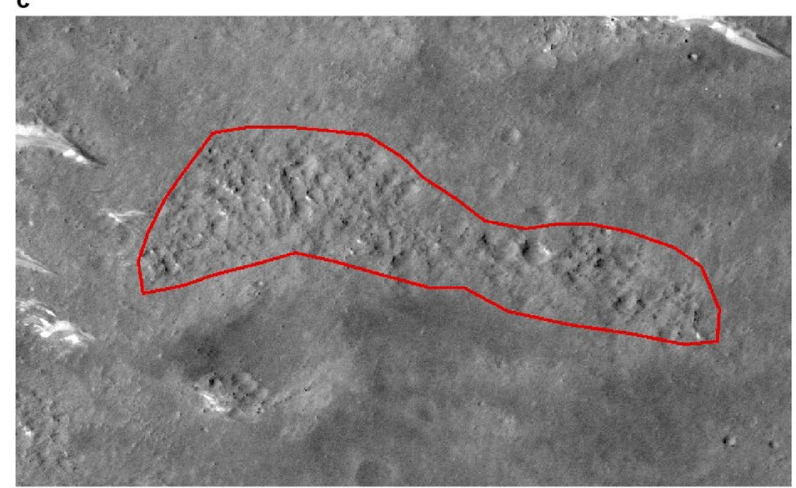

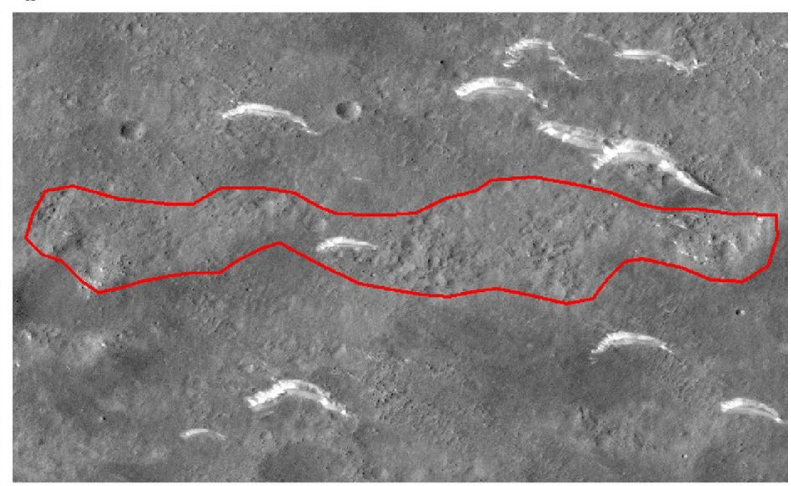

d

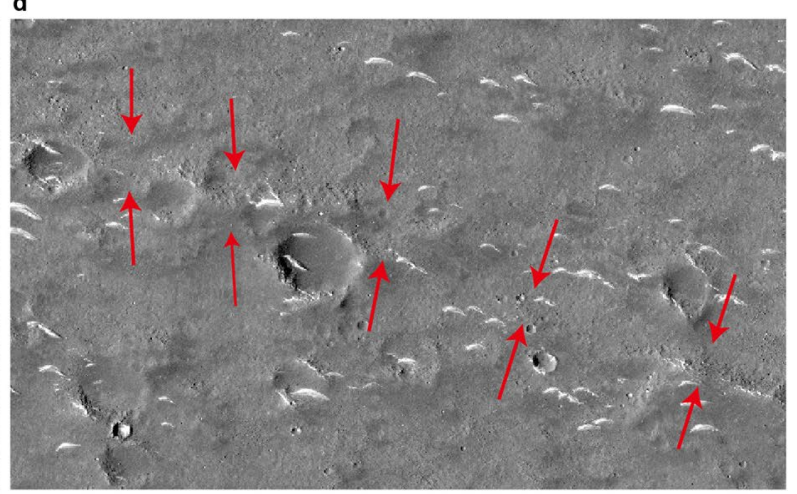

e

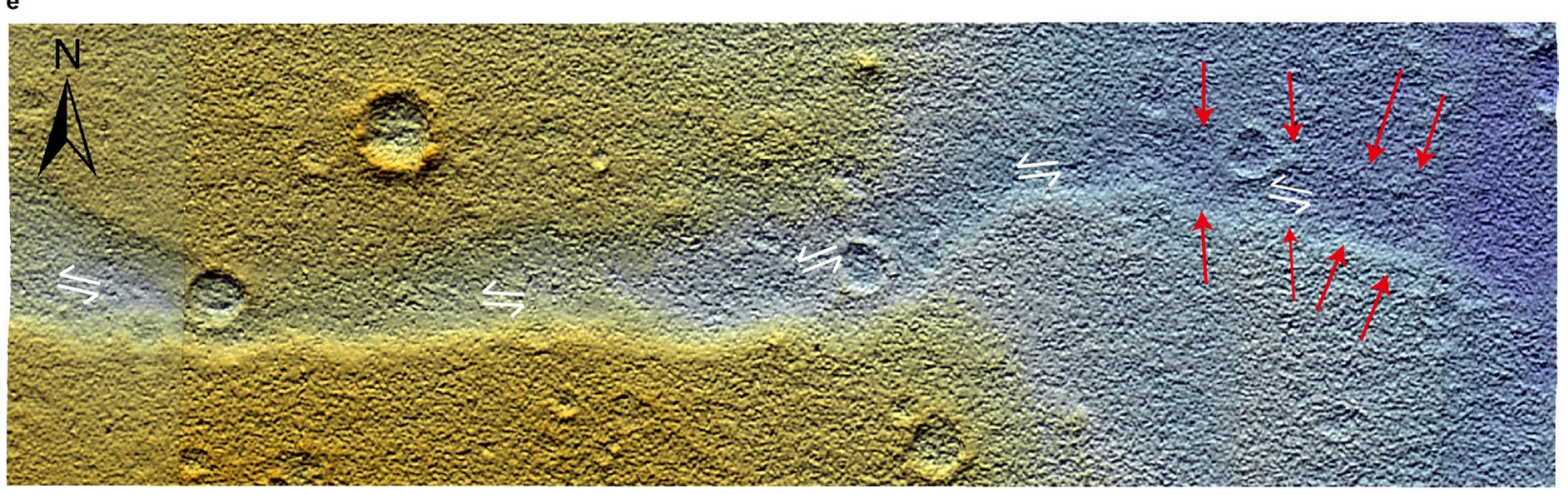

Extended Data Fig. 3 | Views of the five detection targets. a-e represent the five detection targets, respectively. The locations of these targets are marked in Fig. 3. The base map of a-d is HiRISE image (https://www.uahirise.org/ESP_069731_2055). The base map of $\mathbf{e}$ is HiRIC DEM. 


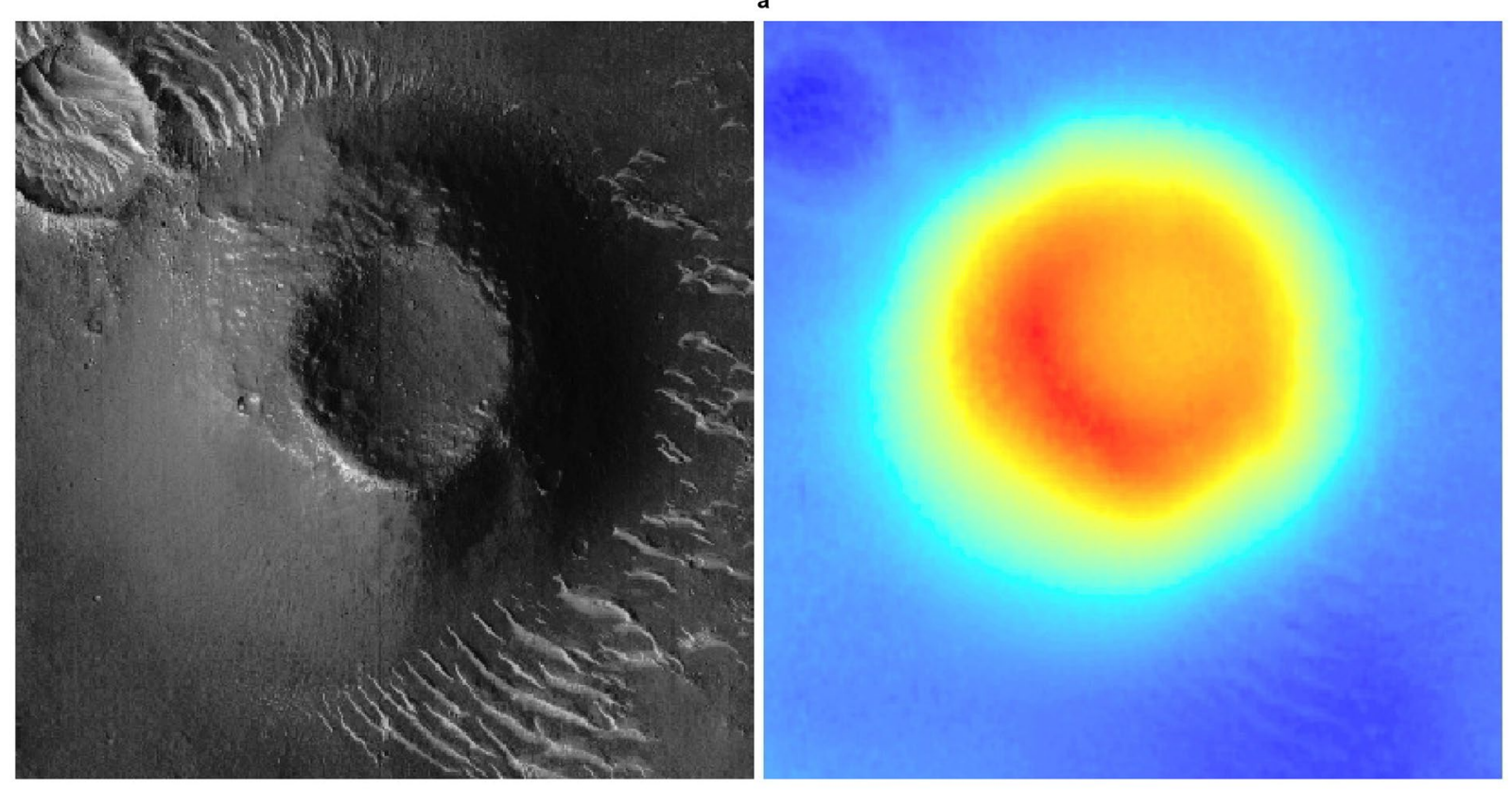

b
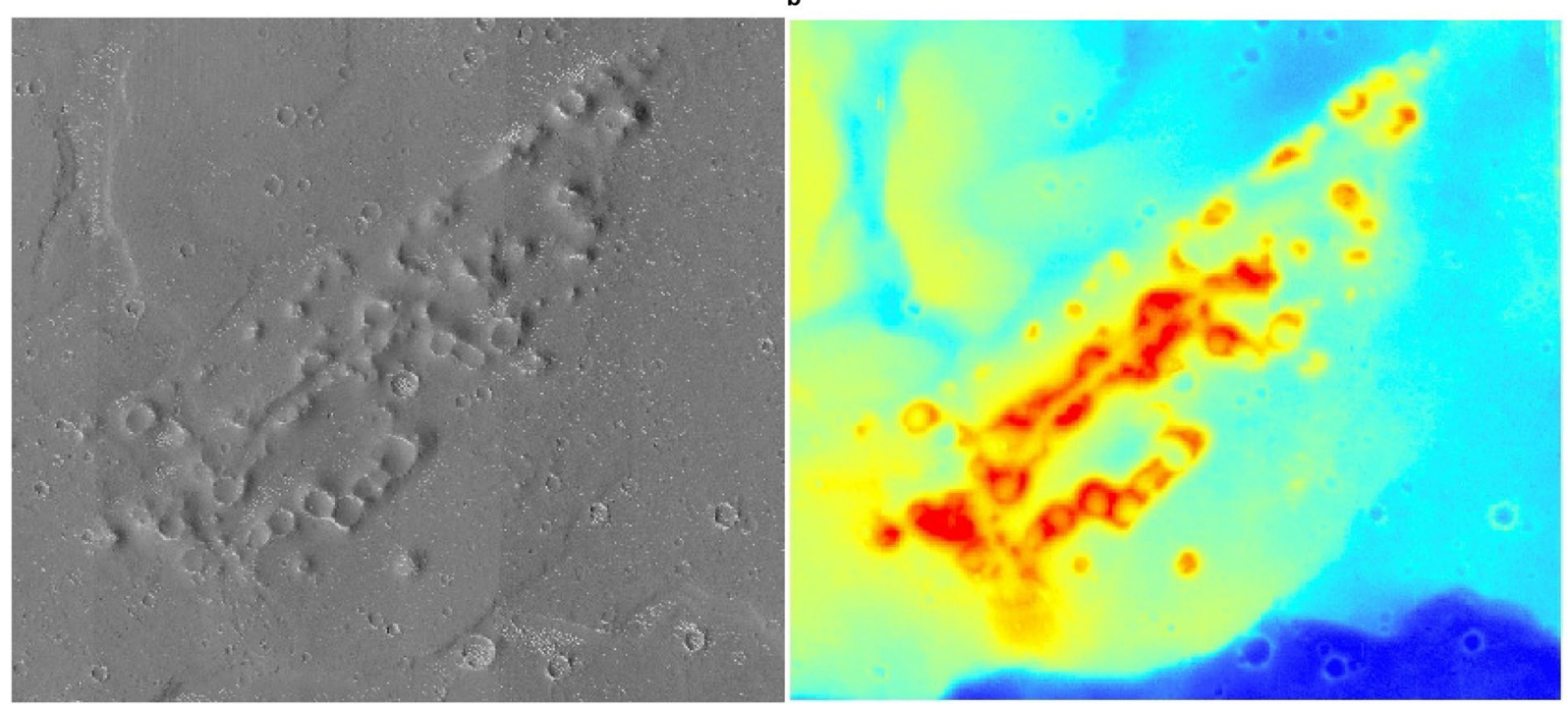

Extended Data Fig. 4 | Isolated and cluster of cones. a, An isolated cone with a height of $80 \mathrm{~m}$ located $\sim 16 \mathrm{~km}$ southeast of the landing site. The diameters of its central pit and basal are of $320 \mathrm{~m}$ and $800 \mathrm{~m}$, respectively. b. A cluster of cones observed in the landing area, located $\sim 24 \mathrm{~km}$ southeast of the landing site. The cluster contains 49 regular and irregular circle cones in a $19 \mathrm{~km}^{2}$ region, with an average height of $70 \mathrm{~m}$. The diameters of the central pits of these cones are range from 85 to $740 \mathrm{~m}$. 